\title{
PENERAPAN FRAMEWORK COBIT UNTUK IDENTIFIKASI TINGKAT KEMATANGAN TATA KELOLA TEKNOLOGI INFORMASI: STUDI KASUS DI FASILKOM UNWIDHA
}

\author{
Agustinus Suradi $^{1 *}$, Sri Wiyanta ${ }^{1}$ \\ ${ }^{1}$ Universitas Widya Dharma \\ *simpati2000@mailcity.com
}

\begin{abstract}
Abstrak
Perkembangan IT sebagai media komunikasi data hingga saat ini berkembang sangat pesat. Peranan teknologi informasi dalam suatu lembaga sangat krusial, namun masalah yang sering terjadi di lembaga/ instansi adalah penggunaan teknologi informasi yang ternyata tidak sesuai dengan harapan, oleh karena itu diperlukan tata kelola terhadap penggunaan teknologi informasi. Permasalahan yang dihadapi di Fasilkom Unwidha adalah adanya ketidakpuasan layanan IT yang diberikan, terdapatnya gangguan layanan yang tidak segera diatasi, adanya koordinasi maintenance infrastruktur IT yang kurang optimal. Sehingga perlu adanya evaluasi terhadap tata kelola teknologi informasi yang diberikan untuk penyelarasan dengan tujuan organisasi agar visi yang diharapkan dapat tercapai. Penelitian ini membahas tentang kondisi tata kelola teknologi informasi di Fasilkom Unwidha, dan sejauh mana telah menerapkan tata kelola teknologi informasi yang baik. Metode analisis yang digunakan dalam penelitian ini adalah dengan menggunakan framework Control Objectives for Information and Related Technology (COBIT). Hasil dari analisis ini berupa tingkat kematangan tata kelola teknologi informasi yang mencerminkan kondisi tata kelola teknologi informasi di Fakultas Ilmu Komputer Unwidha. Tingkat kematangan dengan mengacu pada maturity level yang disediakan kerangka kerja COBIT, diperoleh nilai kematangan 2,84 yaitu pada level Defined Process. Sistem memiliki ruang lingkup Business Goals sebanyak 13, IT Goals sebanyak 18, IT Process sebanyak 30 proses dan 4 Domain.
\end{abstract}

Kata Kunci: IT Governance, maturity level, COBIT.

\section{Pendahuluan}

Pengelolaan sistem informasi yang tepat akan berdampak pada suatu instansi dalam mencapai target tujuannya. Pesatnya perkembangan ilmu pengetahuan dan teknologi khususnya di bidang IT sangat berperan dalam mendukung kemajuan suatu organisasi.

Teknologi Informasi saat ini menjadi bagian yang tak terpisahkan dan terintegrasi dengan tujuan bisnis organisasi. Bagaimana teknologi informasi diaplikasikan dalam suatu organisasi akan mempengaruhi seberapa jauh organisasi tersebut telah mencapai visi, misi, ataupun tujuan strategisnya [1].

Agar implementasi IT Governance pada Fakultas dapat berlangsung secara efektif, organisasi harus dapat mengevaluasi dan menilai sejauh mana IT Governance yang sekarang berlangsung dan mengidentifikasi peningkatan yang dapat dilakukan. Hal tersebut berlaku pada semua proses yang dikelola yang terkandung dalam TI dan proses IT Governance itu sendiri. Pada penelitian [2] pengunaan model maturity dalam hal ini akan memudahkan dalam penilaian dengan cara pendekatan yang terstruktur terhadap skala yang mudah dimengerti dan konsisten .

Berkaitan dengan IT Governance, diperlukan adanya sebuah mekanisme audit terhadap pengelolaan teknologi informasi. Secara umum kerangka kerja tata kelola TI serta pengendalian yang dibutuhkan untuk mencapainya disediakan oleh framework COBIT (Control Objective for Information and related Technology) [3], [4].

Pada penelitian ini bertujuan untuk menganalisis tata kelola IT dan melakukan pengukuran maturity level tata kelola IT di Fasilkom Unwidha agar memberikan pelayanan yang maksimal dan didukung oleh pengelolaan manajemen yang handal sehingga dapat tercapai tujuan organisasi seperti yang diharapkan.

\section{Metode Penelitian}

Metode penelitian yang digunakan yaitu metode kualitatif, prosedur penelitian yang menghasilkan data deskriptif. Dalam penelitian ini akan digunakan studi kasus Fakultas Ilmu Komputer yang bertipe deskriptif dengan tujuan agar peneliti mendapatkan gambaran yang sejelas mungkin mengenai proses tata kelola TI, terutama yang berkaitan dengan efektivitas dan efisiensi.

\subsection{Tahapan Penelitian}

Metode analisis data yang dilakukan dengan menggunakan kerangka kerja yang terdapat dalam Cobit 4.1. Berikut adalah beberapa tahapan yang akan dilakukan dalam analisis data [5]:

Tahap 1 - Gain Understanding.

Tahap 2 - Study Literatur. 


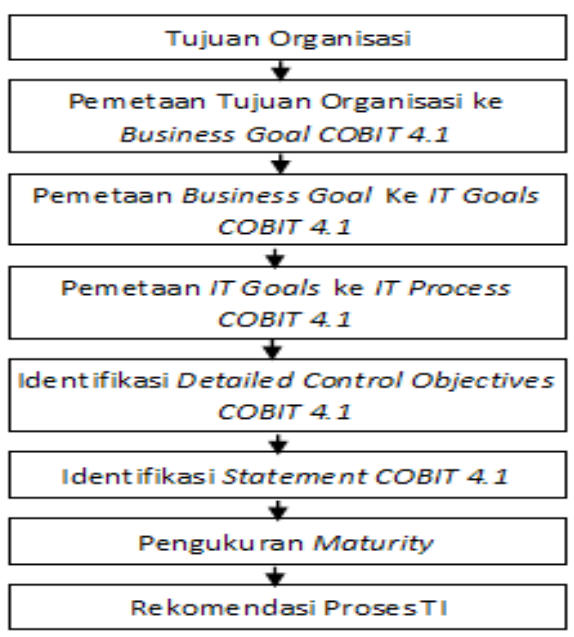

Gambar 1. Alur penelitian

Tabel 1. IT Process dan IT Domain yang Teridentifikasi

\begin{tabular}{ll}
\hline \multicolumn{1}{c}{ IT PROCESS } & \multicolumn{1}{c}{ IT DOMAIN } \\
\hline PO1, PO2, PO3, PO4, & \\
PO5, PO6, PO7, PO8, & Plan and Organise \\
PO9, PO10 & \\
AI1, AI2, AI3, AI4, AI5, & $\begin{array}{l}\text { Acquire and } \\
\text { AI6, AI7 }\end{array}$ \\
DS1, DS2, DS3, DS4, DS5, & \\
DS6, DS7, DS8, DS10, & Deliver and Support \\
DS12, DS13 & \\
ME1, ME4 & $\begin{array}{l}\text { Monitor and } \\
\text { Evaluation }\end{array}$ \\
\hline
\end{tabular}

\footnotetext{
Tahap 3 - Desain Penelitian

Tahap 4 - Pengolahan Data

Tahap 5 - Tahap Analisis Data

Tahap 6 - Penyusunan Laporan
}

\subsection{Teknik Pengumpulan Data}

Dalam COBIT terdapat panduan mengenai kegiatan yang penting untuk dilakukan berkaitan dengan proses tata kelola TI. Oleh karena itu, alat pengumpulan data dikembangkan berdasarkan indikator-indikator kegiatan yang terdapat pada framework COBIT. Data utama dikumpulkan dengan kuesioner dan dilengkapi dengan wawancara, observasi, serta kepustakaan dan dokumen tertulis.

a. Wawancara

Kegiatan ini dilakukan untuk menangkap deskripsi lebih lengkap mengenai masalah yang diteliti yang tidak terjaring melalui kuesioner. Untuk pedoman wawancara, meneliti juga berpedoman pada model kematangan dan Control Objectives COBIT.

b. Observasi

Pengamatan dilakukan terhadap pengelolaan TI berdasarkan aspek-aspek yang telah ditetapkan dalam COBIT.

c. Kuesioner

Untuk kuesioner mengenai tingkat kesadaran pengelolaan mengenai pengelolaan, proses, pengawasan, dan evaluasi TI, peneliti menggunakan COBIT 4.1, yaitu mendata kegiatan-kegiatan yang berhubungan dengan tata kelola TI, apa saja yang dinilai penting menurut COBIT, dan menanyakan tingkat keperluan kegiatan-kegiatan tersebut kepada responden [6]

\subsection{Alur Penelitian}

Berdasarkan tahapan penelitian yang akan dilakukan maka dibuatlah alur penelitian dari pengukuran Maturity Model [7], [8], [9]:

\section{Hasil Penelitian Dan Pembahasan}

Analisis Tata Kelola Teknologi Informasi Dengan Menggunakan COBIT 4.1 Maturity Model dengan:

a. Pemetaan Tujuan organisasi ke Business Goals COBIT 4.1

a) Pemetaan ke COBIT 4.1 IT Goals.

b) Pemetaan ke COBIT 4.1 IT Process.

c) Pemetaan ke Detailed Control Objectives.

d) Dari Detailed Control Objectives ke Statements dalam setiap proses TI

e) Dari Statements dari setiap tingkat dalam setiap proses dinilai berdasarkan cara Pederiva [10].

f) Penilaian tingkat kematangan setiap Proses TI.

g) Penilaian tingkat kematangan setiap Domain TI.

h) Penilaian tingkat kematangan total dari setiap Domain TI.

b. Identifikasi Business Goals COBIT 4.1

Mengidentifikasi tujuan (goals) organisasi selanjutnya dilakukan pemetaan dari tujuan organisasi tersebut dengan business goals yang dimiliki COBIT 4.1. Proses pemetaan dilakukan dengan menghubungkan business goals pada COBIT 4.1

c. Identifikasi IT Goals COBIT 4.1

Setelah mengidentifikasi Tujuan Bisnis, langkah selanjutnya adalah mengidentifikasi Tujuan TI yang sesuai dengan studi kasus Fakultas. COBIT telah memetakan Business Goals dengan IT Goals, dan dari pemetaan tersebut terlihat IT Goals apa saja yang nantinya akan menunjang Business Goals Fakultas.

d. Identifikasi IT Process COBIT 4.1

Setiap tujuan teknologi informasi dapat terdiri atas beberapa proses teknologi informasi yang terkait, demikian juga sebaliknya setiap IT Process dapat digunakan untuk memenuhi beberapa IT Goals. Hasil pemetaan antara IT Goals dan IT Process dalam kerangka kerja COBIT 4.1

Pemetaan IT Process yang dapat diterapkan menghasilkan 30 (tiga puluh) proses. Adapun IT Process yang sesuai dengan IT Goals sebagai berikut: PO1: Define a Strategic Plan

PO2: Define the Information Architecture PO3: Determine Technological Direction PO4: Define the IT Processes, Organization and Relationship

PO5: Manage the IT Investment

PO6: Communicate Management Aims and Direction

PO7: Manage IT Human Resources

PO8: Manage Quality

PO9: Asses and Manage IT Risks

PO10: Manage Projects

AI1: Identify Automated Solution

AI2: Acquire and Maintain Application Software 
- AI3: Acquire and Maintain Technology Infrastructure

AI4: Enable Operation and Use

AI5: Procure IT Resources

AI6: Manage Changes

AI7: Install and Accredit Solutions and Changes

DS1: Define and manage service levels

DS2: Manage third-party services

DS3: Manage performance and capacity

DS4: Ensure continuous service

DS5: Ensure systems security

DS6: Identify and allocate costs

DS7: Educate and train users

DS8: Manage service desk and incidents

DS10: Manage problems

DS12: Manage the physical environment

DS13: Manage operations

- ME1: Monitor and Evaluate IT Performance

- ME4: Provide IT Governance

e. Tingkat Kematangan Tata Kelola TI

Hasil pemetaan IT Process di Fasilkom dengan COBIT 4.1 menghasilkan 30 Proses TI. Proses tersebut kemudian dinilai menggunakan COBIT 4.1 Maturity Model. Tabel berikut merupakan hasil penilaian terhadap IT Process:

Tabel 2. Tingkat Kematangan IT Process Domain PO

\begin{tabular}{|c|c|c|c|}
\hline \multicolumn{4}{|c|}{ MATURITY LEVEL } \\
\hline \multicolumn{2}{|c|}{ Domain } & \multicolumn{2}{|l|}{ Plan and Organise (PO) } \\
\hline No. & Kode & Proses TI & Nilai \\
\hline 1 & PO1 & Define a Strategic Plan & 2,71 \\
\hline 2 & PO2 & $\begin{array}{c}\text { Define the Information } \\
\text { Architecture }\end{array}$ & 2,97 \\
\hline 3 & PO3 & $\begin{array}{c}\text { Determine Technological } \\
\text { Direction }\end{array}$ & 2,94 \\
\hline 4 & PO4 & $\begin{array}{l}\text { Define the IT Processes, } \\
\text { Organization and Relationship }\end{array}$ & 2,80 \\
\hline 5 & PO5 & Manage the IT Investment & 2,93 \\
\hline 6 & PO6 & $\begin{array}{c}\text { Communicate Management } \\
\text { Aims and Direction }\end{array}$ & 2,34 \\
\hline 7 & PO7 & Manage IT Human Resources & 2,82 \\
\hline 8 & PO8 & Manage Quality & 2,46 \\
\hline 9 & PO9 & Asses and Manage IT Risks & 2,71 \\
\hline 10 & PO10 & Manage Projects & 2,42 \\
\hline & & Nilai Total & 27,09 \\
\hline \multicolumn{3}{|c|}{ Nilai kematangan Plan and Organise (PO) } & 2,71 \\
\hline
\end{tabular}

Tabel 3. Tingkat Kematangan IT Process Domain AI

\section{MATURITY LEVEL}

\begin{tabular}{|c|c|c|c|}
\hline \multicolumn{2}{|c|}{ Domain } & \multicolumn{2}{|c|}{ Acquire and Implement (AI) } \\
\hline No. & Kode & Proses TI & Nilai \\
\hline 1 & AI1 & Identify Automated Solution & 2,65 \\
\hline 2 & AI2 & $\begin{array}{c}\text { Acquire and Maintain Application } \\
\text { Software }\end{array}$ & 2,64 \\
\hline 3 & $\mathrm{AI} 3$ & $\begin{array}{c}\text { Acquire and Maintain Technology } \\
\text { Infrastructure }\end{array}$ & 2,34 \\
\hline 4 & AI4 & Enable Operation and Use & 2,74 \\
\hline 5 & AI5 & Procure IT Resources & 2,58 \\
\hline 6 & AI6 & Manage Changes & 2,98 \\
\hline 7 & AI7 & $\begin{array}{c}\text { Install and Accredit Solutions and } \\
\text { Changes }\end{array}$ & 2,55 \\
\hline & & Nilai Total & 18,48 \\
\hline & kemata & $\begin{array}{l}\text { fan Domain Acquire and Implement } \\
\text { (AI) }\end{array}$ & 2,64 \\
\hline
\end{tabular}

MATURITY LEVEL

\begin{tabular}{cccc}
\hline \multicolumn{3}{c}{ Domain } & \multicolumn{2}{c}{ Deliver and Support (DS) } \\
\hline No. & Kode & Proses TI & Nilai \\
\hline 1 & DS1 & Define and manage service levels & 3,26 \\
2 & DS2 & Manage third-party services & 3,09 \\
3 & DS3 & Manage performance and capacity & 3,26 \\
4 & DS4 & Ensure continuous service & 3,30 \\
5 & DS5 & Ensure systems security & 3,25 \\
6 & DS6 & Identify and allocate costs & 3,35 \\
7 & DS7 & Educate and train users & 3,25 \\
8 & DS8 & Manage service desk and incidents & 3,24 \\
9 & DS10 & Manage problems & 3,14 \\
10 & DS12 & Manage the physical environment & 2,99 \\
11 & DS13 & Manage operations & 2,91 \\
\hline \multirow{4}{*}{ Nilai kematangan Deliver and Support (DS) } & 3,19 \\
\hline
\end{tabular}


Tabel 5. Tingkat Kematangan IT Process Domain ME

MATURITY LEVEL

\begin{tabular}{cccc}
\hline \multicolumn{2}{c}{ Domain } & \multicolumn{3}{c}{ Monitor and Evaluate (ME) } \\
\hline No. & Kode & Proses TI & Nilai \\
\hline 1 & ME1 & $\begin{array}{c}\text { Monitor and Evaluate IT } \\
\text { Performance }\end{array}$ & 2,47 \\
2 & ME4 & Provide IT Governance & 3,18 \\
\hline \multicolumn{3}{c}{ Nilai Total } \\
\hline \multicolumn{3}{c}{ Nilai kematangan Monitor and } \\
Evaluate $(M E)$
\end{tabular}

\section{GRAFIK MATURITY LEVEL}

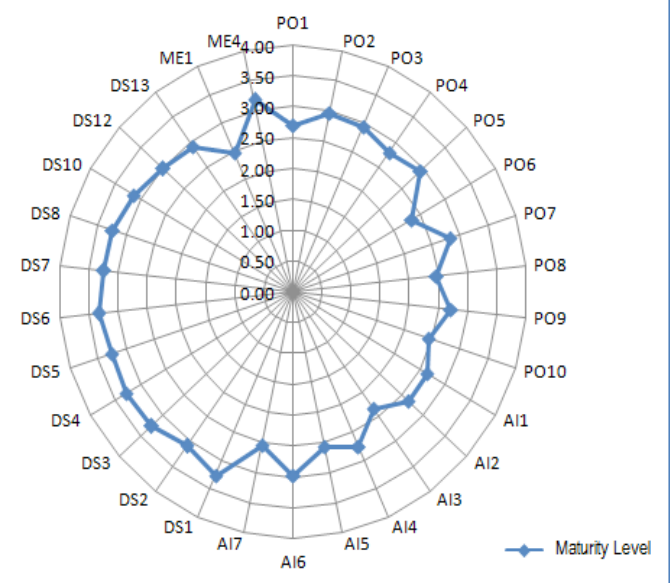

Gambar 2. Radar Chart Nilai kematangan IT Process Fasilkom

Tabel 6. Tingkat Kematangan Total IT Process

COBIT 4.1 MATURITY LEVEL

\begin{tabular}{cc}
\hline Domain & Nilai \\
\hline Plan and Organise (PO) & 2,71 \\
Acquire and Implement (AI) & 2,64 \\
Deliver and Support (DS) & 3,19 \\
Monitor and Evaluate (ME) & 2,83 \\
Nilai Total & 11,36 \\
Nilai kematangan Total IT Process & 2,84 \\
\hline
\end{tabular}

Dari penilaian tersebut dapat dikelompokkan, yaitu: Kategori pertama merupakan proses pada Repeatable but intuitive terdiri atas 5 proses, yaitu:

- PO6 Communicate management aims and direction, nilai 2,34

PO8 Manage quality buman resource, nilai 2,46

PO10 Manage projects, nilai 2,42

- AI3 Acquire and maintain technology infrastructure, nilai 2,34

- ME1 Monitor and evaluate IT performance, nilai 2,47

Kategori kedua merupakan proses pada tahap Defined Process yang terdiri atas 25 proses, yaitu:
PO1 Define a strategic IT plan, nilai 2,71

PO2 Define the information architecture, nilai 2,97

PO3 Determine technological direction, nilai 2,94

PO4 Define the IT processes, organization and relationships, nilai 2,80

PO5 Manage the IT investment, nilai 2,93

PO7 Manage IT buman resources, nilai 2,82

PO9 Asses and manage IT risks, nilai 2,71

AI1 Identify automated solutions, nilai 2,65

AI2 Acquire and maintain application software, nilai 2,64

AI4 Enable operation and use, nilai 2,74

AI5 Procure IT resources, nilai 2,58

AI6 Manage changes, nilai 2,98

AI7 Install and accredit solutions and changes, nilai 2,55

DS1 Define and manage service levels, nilai 3,26

DS2 Manage third-party services, nilai 3,09

DS3 Manage performance and capacity, nilai 3,26

DS4 Ensure continuous service, nilai 3,30

DS5 Ensure systems security, nilai 3,25

DS6 Identify and allocate costs, nilai 3,35

DS7 Educate and train users, nilai 3,25

DS8 Manage service desk and incidents, nilai 3,24

DS10 Manage problems, nilai 3,14

DS12 Manage the physical environment, nilai 2,99

DS13 Manage operations, nilai 2,91

ME4 Provide IT Governance, nilai 3,18

Dari hasil nilai kematangan proses TI di atas dapat diperoleh nilai kematangan total proses TI, sebagai berikut:

Sehingga dari hasil penilaian diperoleh hasil tingkat kematangan proses tata kelola TI dengan nilai total kematangan 2,84 yaitu pada level Define Process, artinya sudah ada prosedur yang memiliki standar dan didokumentasikan dengan baik, sudah ada pelatihan formal untuk mengkomunikasikan prosedur dan kebijakan yang dibuat. Tetapi pada tahap implementasinya masih tergantung pada individu apakah mau melakukan prosedur yang ditetapkan atau tidak. Prosedur yang dibuat masih terbatas pada bentuk formalisasi dari praktik yang ada.

f. Analisis Rekomendasi Tata Kelola TI

Pada proses TI PO6 (Communicate management aims and direction), PO8 (Manage quality buman resource), PO10 (Manage projects), AI3 (Acquire and maintain technology infrastructure), ME1 (Monitor and evaluate IT performance), pada level 2 (Repeatable but Intuitive), maka perlu adanya perbaikan untuk dapat ditingkatkan kematangannya. Agar proses PO6, PO8, PO10, AI3, dan ME1 dapat mencapai maturity level 3, maka yang perlu dilakukan adalah:

- PO6 (Communicate management aims and direction):

- Kerangka kerja, kebijakan, perencanaan, dan prosedur dikembangkan, didokumentasikan, dan dikomunikasikan oleh pihak manajemen.

- Proses pengembangan kebijakan yang terstruktur, dipelihara, dan mendapat dukungan oleh staff

- Adanya teknik untuk mempromosikan 
kesadaran keamanan TI telah dibakukan dan diformalkan

- Ada kerangka kerja pengembangan global.

- PO8 (Manage quality buman resource):

- Sebuah proses Quality Management System dikomunikasikan ke semua unsur oleh manajemen dan melibatkan TI dan pengguna akhir manajemen.

- Adanya sebuah program pendidikan dan pelatihan untuk mengajarkan ke semua tingkat organisasi tentang kualitas.

- Adanya alat umum dan praktik manajemen mutu yang muncul.

- Kualitas survei kepuasan direncanakan dan kadang-kadang dilakukan.

- PO10 (Manage projects):

- Proses dan metodologi manajemen proyek TI perlu ditetapkan dan dikomunikasikan.

- Senior TI dan pihak manajemen mulai berkomitmen dan terlibat dalam pengelolaan proyek-proyek TI.

- Proyek TI yang ditugaskan perlu ada target bisnis dan teknis

- Proyek TI dipantau anggaran dan pengukuran kinerjanya

- $\quad$ AI3 (Acquire and maintain technology infrastructure):

- Perlu pendefinisian yang jelas untuk mendapatkan dan memelihara infrastruktur TI.

- Pemeliharaan infrastruktur TI direncanakan dijadwalkan dan dikoordinasikan.

- ME1 (Monitor and evaluate IT performance):

- Alat untuk memantau proses dan layanan didefinisikan.

- Adanya pengukuran kinerja TI, pengukuran strategis, dan pengukuran kepuasan pelanggan.

- Menetapkan sebuah kerangka kerja untuk mengukur kinerja.

\section{Kesimpulan}

Hasil penelitian ini menunjukkan pengukuran tingkat kematangan proses tata kelola TI di Fasilkom Unwidha dengan COBIT 4.1 maturity model memiliki ruang lingkup Business Goals sebanyak 13, IT Goals sebanyak 18, IT Process sebanyak 30 proses, dan 4 Domain.

Untuk analisis kematangan tata kelola TI, dapat dikelompokkan menjadi 2 yaitu: kategori pertama merupakan proses pada level Repeatable but Intuitive terdiri atas 5 proses, yaitu: PO6 ,PO8, PO10, AI3, ME1, dan kategori kedua merupakan proses pada level Defined Process yang terdiri atas 25 proses, yaitu: PO1, PO2, PO3, PO4, PO5, PO7, PO9, AI1, AI2, AI4, AI5, AI6, AI7, DS1, DS2, DS3, DS4, DS5, DS6, DS7, DS8, DS10, DS12, DS13, ME4.
Hasil pengukuran tingkat kematangan tata kelola TI diperoleh nilai kematangan 2,84 yaitu pada level Define Process, artinya sudah ada prosedur yang memiliki standar dan didokumentasikan dengan baik, sudah ada pelatihan formal untuk mengkomunikasikan prosedur dan kebijakan yang dibuat. Tetapi pada tahap implementasinya masih tergantung pada individu apakah bersedia melakukan prosedur yang ditetapkan atau tidak. Prosedur yang dibuat masih terbatas pada bentuk formalisasi dari praktik yang ada.

\section{Daftar Pustaka}

[1] Riyanto Sarno, Strategi Sukeses Bisnis dengan Teknologi Informasi Berbasis Balanced Scorecard \& COBIT. Surabaya: ITS Press, 2009.

[2] Jorge Robeiro dan Rui Gomes, "IT governance using COBIT implemented in a high public educational institution: a case study," In Proceedings of the 3rd international conference on European computing conference, hal. 41-52, 2009.

[3] Dimas Riadi, "Pengukuran Tingkat Kematangan Proses Tata Kelola Teknologi Informasi Dengan Menggunakan Cobit 4.1 Maturity Model: Studi Kasus Dinas Pendidikan DKI Jakarta," Tesis 2013.

[4] Andrea Pederiva, "The COBIT Maturity Model in a Vendor Evaluation Case," Information Systems Control Journal US A, vol. 3, pp. 2-3, 2003.

[5] H.M Jogiyanto, Model Kesuksesan Teknologi Informasi. Yogyakarta: C.V Andi Offset, 2007.

[6] ISACA, Integrating COBIT into the IT Audit Process (Planning, Scope Development, Practise): IT Governance Institute, 2006.

[7] ISACA, COBIT 4.1: Framework, Control Objective,Management Guidelines, Maturity Models.: IT Governance Institute, 2007.

[8] S. Gondodiyoto, Audit Sistem Informasi: Pendekatan Cobit, Edisi Revisi ed. Jakarta: Mitra Wacana Media, 2007.

[9] Christian J. Blunt dan Michael J. Hine, "Using COBIT to guide the adoption of Enterprise 2.0 technologies." Journal of Applied Computing and Information Technology vol. 7, no.1, 2009.

[10] Zainal A.Hasibuan Ph.D, Metodologi penelitian pada bidang ilmu komputer dan teknologi informasi. Fakultas Ilmu Komputer Universitas Indonesia, 2007. 